\title{
Parental Distress as a Mediator of Problem Behaviors in Sons of Alcohol-Involved Families*
}

\author{
Alexandra Loukas,** Lisa A. Piejak, C. Raymond Bingham, Hiram E. Fitzgerald, and Robert A. Zucker \\ Structural equation modeling was used to test the hypothesis that parental distress would mediate the relations between parental lifetime \\ alcohol and physical health problems and child behavior problems. Participants were 182 alcohol-involved families and 83 matched \\ controls with 3- to 5-year-old biological sons. Results show that sons of parents with alcohol and physical health problems are at \\ elevated risk for behavior problems, partly related to the increased levels of distress their parents are experiencing.
}

$\mathrm{C}$ hildren of alcoholics (COAs) are at increased risk for a number of negative developmental outcomes including behavior problems (West \& Prinz, 1987). However, COAs show a great deal of variability in outcome (Johnson \& Jacob, 1995), suggesting the involvement of multiple factors in the development of behavioral difficulties. Being the child of an alcoholic may not be the sole determinant of negative outcomes; other variables also may play a role. For instance, the homes of alcoholics have been characterized by high marital discord, inadequate parenting, and low levels of positive stimulation (Reich, Earls, \& Powell, 1988).

Many researchers have examined variables in addition to parental alcoholism that may be associated with child outcome, including parental antisocial behavior, stress, and depression (see Kuperman, Schlosser, Lidral, \& Reich, 1999; Rubio-Stipec, Bird, Canino, Bravo, \& Alegria, 1991; Zucker, Ellis, \& Fitzgerald, 1994). Fewer researchers have considered the relations among parental physical health history and these risk factors. Moreover, little work has examined the impact of parental health history on the behavioral development of COAs, even though individuals who drink heavily report elevated levels of health problems (Chou, Grant, \& Dawson, 1996) and parental physical symptomatology has been found to be an important predictor of maladjustment in non-COA samples (Stein \& Newcomb, 1994).

Research examining the role of parental physical health on child adjustment has focused almost exclusively on differentiating children of physically ill parents from children of parents who are not ill on a variety of factors, with little effort directed toward examining the processes affecting the relationship between parental physical health and child outcome (see Armistead, Klein, \& Forehand, 1995, for a review). Likewise, although COAs are at heightened risk for behavioral problems, the pathways through which parental alcoholism influences child

*This work was supported in part by a grant from the National Institute on Alcohol Abuse and Alcoholism (RO1 AA07065) awarded to R. A. Zucker and H. E. Fitzgerald.

**Address correspondence to: Alexandra Loukas, Ph.D., Department of Kinesiology \& Health Education, University of Texas at Austin, Austin, TX 78712; (512) 471-4405; FAX (512) 471-3845; e-mail: alexandra.loukas@mail.utexas.edu

Key Words: child behavior problems, children of alcoholics, parent alcoholism, parent antisocial behavior, parent distress, parent physical health.

(Family Relations, 2001, 50, 293-301) outcomes are not yet well understood, particularly with respect to the behavioral development of preschool-aged children.

The purpose of the present study was to examine the processes through which parent lifetime alcohol-related psychopathology and physical health problems are related to the development of behavior problems in 3- to 5-year-old male children. We hypothesized that lifetime levels of parent alcohol-related psychopathology and health problems would be indirectly related to child outcome through current levels of parental distress (daily hassles, stress and depression). Thus, we expected that current levels of parent distress would mediate or account for the relations between parent lifetime alcohol-related psychopathology and health history and the young son's behavior problems (see Figure 1).

\section{Parent Alcohol-Related Psychopathology}

It is by now well accepted that there is more than one type of alcoholic, and children may be differentiated on the basis of the type of alcoholism their parent (or parents) exhibits (Puttler, Zucker, Fitzgerald, \& Bingham, 1998). In particular, the presence of comorbid antisocial personality disorder not only strongly differentiates the clinical severity and onset characteristics of the adult alcohol disorder (Babor et al., 1992; Cloninger, 1987) but also discriminates spouse and child characteristics (Puttler et al.; Zucker, Ellis, et al., 1994). For example, antisocial alcoholics (AALs) exhibit significantly more antisocial behavior in childhood and adulthood, have an earlier age of onset for drinking problems, more alcohol-related problems, and a longer duration of use than nonantisocial alcoholics (NAALs; Zucker, Ellis, Fitzgerald, Bingham, \& Sanford, 1996). AALs and their spouses also report experiencing more depression, marital conflict, family violence, marital instability, and a lower attained socioeconomic status. Moreover, the children of AALs exhibit more behavioral problems than do the children of NAALs, followed by the children of nonalcoholic controls (Zucker, Ellis, et al., 1994). Because the presence of co-occurring antisocial behavior is likely indicative of a denser history of parent psychopathology, increased levels of family stress, a poorer-quality family environment, and increased risk for negative COA outcomes, we examined the contribution of parent lifetime alcohol problems and antisocial behavior as indicators of parent alcohol-related psychopathology. 


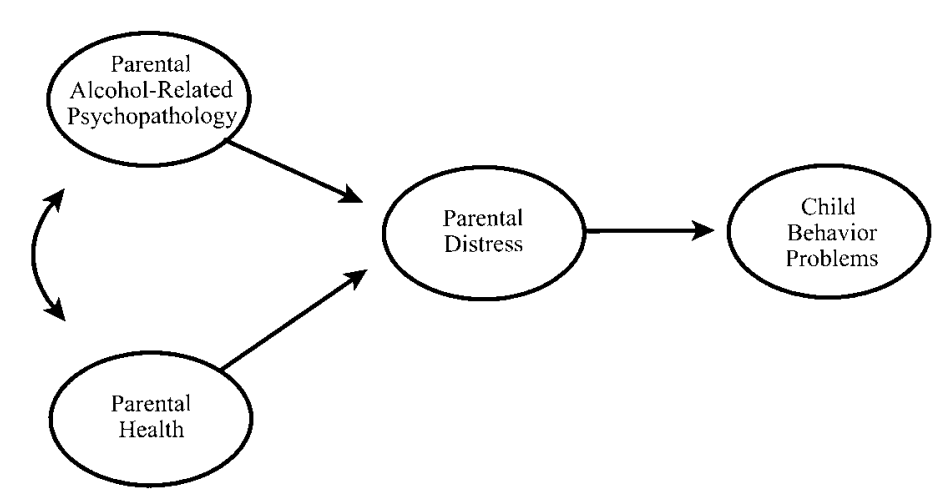

Figure 1. Hypothetical Model With Parental Distress as a Mediator of the Relations Between Parental Alcohol-Related Psychopathology and Physical Health and the Child Behavior Problems Outcome

\section{Parent Physical Health Problems}

Individuals with alcoholism and other alcohol-related problems are also at elevated risk for physical health complications, including medical disorders, malnutrition, and incidence of trauma (Dufour \& Caces, 1993; Glenn, Parsons, \& Stevens, 1989; Marsano, 1993). One possible consequence of heavy alcohol consumption is acute upper-respiratory infections that are not related to smoking (Engs \& Aldo-Benson, 1995). These infections may be related to depressed immune system functioning (Grossman \& Wilson, 1992) caused not solely by alcohol consumption, but also by related factors such as stress and erratic sleeping and eating patterns (Engs \& Aldo-Benson; Roselle, 1992). Thus, factors related to a lifestyle characterized by heavy alcohol consumption may play an important role in worsening health.

Immediate family members of individuals with alcohol problems also report more physical health problems. For instance, females in alcoholic families have higher clinic utilization rates, higher diagnosis rates, and higher proportions of diagnoses of trauma and stress-related diseases than females in nonalcoholic families (Roberts \& Brent, 1982). Research has indicated that the increased incidence of trauma and stress-related diseases may be caused by either the direct effects of living with an alcoholic (e.g., violence or abuse) or the indirect effects of increased stress resulting from living with an alcoholic (Roberts $\&$ Brent). Thus, it may be expected that individuals with more lifetime alcohol-related psychopathology also would report a denser history of physical health problems as well as more hospitalizations resulting from these problems. In the current study, we assessed the frequency of typical or acute health problemsphysical problems that may interfere with daily functioning but that are not life-threatening and do not lead to a shortened life span (e.g., frequent headaches, backaches, intestinal problems).

\section{Parent Distress}

Stress often co-occurs with depression (Hammen, 1992; Lazarus \& Folkman, 1984); consequently, in the current study both are conceptualized as indicators of parental distress, the putative mediator through which parental lifetime alcohol-related psychopathology and health problems are related to child behavior problems. A history of parental physical health problems may contribute to increasing current levels of parental distress. For example, DeLongis, Coyne, Dakof, Folkman, and Lazarus (1982) reported that among a middle-aged sample, daily hassles stress was significantly correlated with poorer overall health status. However, because the study was cross-sectional, the direction of effects is unclear. Increased levels of physical health problems also are related to increased levels of depression. Although much research has focused on the association between chronic health problems (e.g., chronic pain, rheumatoid arthritis, cirrhosis of the liver) and depression (Ahles, Khan, Yunus, Spiegel, \& Masi, 1991; Banks \& Kerns, 1996), little has attempted to discern the nature of the association between increased rates of acute health problems and depression. Thus, an important contribution of this study to the literature will be an examination of the relationship between the incidence rate of typical health problems and distress in a community-based sample.

\section{Distress and Child Behavior Problems}

A large body of research exists documenting the contributions of parent stress and depression to both child internalizing and externalizing problems. Findings from these studies reveal positive associations among parental stress, depression, and ratings of child behavioral problems (see Cummings \& Davies, 1994; Harnish, Dodge, \& Valente, 1995). The role of parental distress in child behavioral difficulties may be conceptualized within a social learning perspective. From this perspective, parents who are experiencing elevated levels of distress, such as those who report heightened stress and depression, often lack appropriate family management skills and therefore place their children at risk for problematic outcomes (e.g., Patterson \& Capaldi, 1991). Distressed parents are vulnerable to using coercive behaviors to gain control over chaotic environments and often fail to appropriately monitor their child's behaviors (Patterson, 1992). Consequently, children who are repeatedly exposed to coercive interactions learn directly from their parents to also exhibit coercive and antisocial behaviors, and thus they are at elevated risk for a variety of behavioral difficulties.

\section{Overview of Current Study}

The current study tested the hypothesis that a history of parental alcohol-related psychopathology and health problems would be indirectly related to child behavioral problems through current levels of parent distress. To improve upon previous studies and to assess the full repertoire of child behaviors, we attained both maternal and paternal reports of their son's behavior problems. Although most previous studies have relied upon mothers as informants of their preschool-aged child's behaviors, fathers also are likely to affect child outcomes and to provide a unique assessment of their sons' behaviors (see Phares \& Compas, 1992). For example, because fathers are likely to engage in gender-stereotyped activities with their sons (Siegal, 1987), they may be more willing than are mothers to promote and reinforce inappropriate child behaviors, and thus fathers may report behaviors to which the mother is not exposed. This may be particularly true for fathers who are alcoholic and antisocial, because they may be more apt than their counterparts to model coercive and antisocial behaviors for their male children (see Zucker, Ellis, Bingham, \& Fitzgerald, 1996). 


\section{Method}

\section{Research Participants}

Subjects for the present study were 265 intact families, all of whom had a 3- to 5-year-old biological son $(N=265)$. Families were participating in an ongoing longitudinal study tracking the development of children being reared in high-risk environments characterized by parental alcohol abuse and related comorbidities (Zucker et al., 2000). Data included in the present investigation were drawn from the first wave of the longitudinal study.

Recruitment procedures for the larger study have been described elsewhere in detail (see Zucker, Ellis, \& Bingham, et al., 1996; Zucker et al., 2000). Briefly, the sample for this study included 182 alcoholic families and 83 nonalcoholic families. Alcoholic families were recruited by way of fathers' drinking status in one of two ways. The first group of alcoholic fathers and their families $(n=141$; maternal mean age $=29.5$ years, $S D=4.5$ years; paternal mean age $=31.6$ years, $S D=4.8$ years; child mean age $=4.4$ years, $S D=1.1$ years) was recruited by way of a net of administrative arrangements covering five local district courts and all drunk-driving convictions in a four-county area in mid-Michigan. The fact that the men in this alcoholic group were convicted drunk drivers indicated that their alcoholism was more heavily combined with antisociality than is true of other alcoholics (Cloninger, 1987). At initial contact, a positive alcoholism diagnosis was established using the Short Michigan Alcoholism Screening Test (Selzer, 1975) and was subsequently verified by way of the National Institute of Mental Health Diagnostic Interview Schedule, Version III (NIMH DIS; Robins, Helzer, Croughn, \& Ratcliffe, 1980). All of the men in the alcoholic group received a "definite" or "probable" diagnosis for alcoholism using the Feighner Diagnostic Criteria (Feighner et al., 1972) with 92\% receiving a "definite" diagnosis. Maternal drinking status was assessed, but maternal alcoholism was neither a requirement for inclusion nor a basis for exclusion from the study for the at-risk families.

The second group of alcoholic fathers and their families ( $n$ $=41$ ) was recruited from the neighborhoods in which the drunk driver alcoholic fathers resided (maternal mean age $=33.6$ years, $S D=3.5$ years; paternal mean age $=36.7$ years, $S D=$ 6.3 years; child mean age $=4.3$ years, $S D=0.9$ years). These families were accessed during neighborhood canvasses for nonalcoholic control families (described later). Thus, they provided an ecologically comparable subset of high-risk families drawn out of the same social stratum as the drunk drivers, but their alcoholism was identified by way of community survey.

The 83 nonalcoholic families (maternal mean age $=31.5$ years, $S D=3.8$ years; paternal mean age $=33.0$ years, $S D=$ 4.5 years; child mean age $=4.2$ years, $S D=1.0$ years) were recruited using door-to-door canvassing starting one block away from the alcoholic family and staying within the same census area where possible. The basis for choosing these families was geographic proximity and having a same-aged biological son (within 6 months) as the same-neighborhood alcoholic family. It was required that neither parent in this group of families receive an alcohol diagnosis based on the criteria of Feighner et al. (1972)

\section{Data Collection}

Data were collected by trained project staff who were blinded to each family's risk status. Because of the large volume of data collected, a number of contacts with the family were necessary. Wave 1 data collection took place across nine data collection sessions, seven of which took place in the family home and two of which took place on a university campus. The visits involved 9-10 hours of contact time for each parent and 7 hours for the target child. Contacts included questionnaire sessions, semistructured interviews, and interactive tasks.

\section{Measures}

\section{Parental Alcohol-Related Psychopathology}

Parental lifetime alcohol problems. The Lifetime Alcohol Problems Score (LAPS; Zucker, 1991; Zucker, Davies, Kincaid, Fitzgerald, \& Reider, 1997), calculated for both mothers and fathers, was the primary alcohol involvement variable used in the present analyses. The score was designed to assess differences in the extent of drinking problems over the life course and was derived from information gained from the administration of the Drinking and Drug History Interview (Zucker, Fitzgerald, \& Noll, 1990), the NIMH DIS (Robins et al., 1980), and the short form of the Michigan Alcoholism Screening Test (Selzer, 1975). The LAPS provides a composite score derived from three component subscores: (a) the primacy component, measuring the age at which the respondent reported first drinking enough to get drunk; (b) the variety component, measuring the number of areas in which drinking problems were reported (i.e., work, family, etc.); and (c) the life percentage component, measuring the interval between the most recent and the earliest drinking problems, corrected for current age. A higher LAPS score reflects more problems related to drinking.

Parental lifetime antisocial behavior. To assess antisociality, each parent independently completed the Antisocial Behavior Checklist (ASBCL; Zucker \& Noll, 1980). The ASBCL is a 46item revision of an earlier antisocial behavior inventory used in the Rutgers Community Study (Zucker \& Barron, 1973) that has been modified such that items are salient for both adult and adolescent antisocial activities. The ASBCL measures the frequency of the parent's participation in a variety of aggressive and antisocial activities both in adolescence (e.g., lying to parents, being suspended from school) and adulthood (e.g., being fired, resisting arrest, defaulting on a debt). The scores for each item range from 0 (never) to 3 (often). Higher scores on the ASBCL reflect more antisocial behavior.

A series of reliability and validity studies on populations ranging from male and female college students to male and female prison inmates has shown that the ASBCL has adequate test-retest reliability (.91 over 4 weeks) and internal consistency (coefficient $\alpha=.93$ ). The ASBCL also differentiates among groups with major histories of antisocial behavior (e.g., inmates) versus individuals with minor offenses in district court versus university students (Zucker \& Noll, 1980), and it also differentiates between alcoholic and nonalcoholic adult males (Zucker, Noll, Ham, Fitzgerald, \& Sullivan, 1994).

\section{Parental Health}

Parental health was operationalized as the number of illnesses and hospitalizations each parent independently reported on the Health History Questionnaire (Carpenter \& Lester, 1980). This self-report questionnaire was developed by the Rutgers Longitudinal Study and assesses parental health and illness history. The frequency of hospitalizations was taken from the hos- 
Means, Standard Deviations, and Correlations for All Measures for Entire Sample $(N=265)$

\begin{tabular}{|c|c|c|c|c|c|c|c|}
\hline & 1 & 2 & 3 & 4 & 5 & 6 & 7 \\
\hline 1. Maternal antisociality & & $.32 * * * *$ & $.52 * * * *$ & $.33 * * * *$ & $.21 * * * *$ & .10 & $.13 * *$ \\
\hline 2. Paternal antisociality & & & $.19 * * *$ & $.57 * * * *$ & $.10 *$ & .09 & -.03 \\
\hline 3. Maternal LAPS & & & & $.27 * * * *$ & $.23 * * * *$ & $.13 * *$ & .11 \\
\hline 4. Paternal LAPS & & & & & .07 & .11 & $-.01 *$ \\
\hline 5. Maternal illness & & & & & & $.28 * * * *$ & $.24 * * * *$ \\
\hline 6. Paternal illness & & & & & & & .07 \\
\hline 7. Maternal hospitalizations & & & & & & & \\
\hline 8. Paternal hospitalizations & & & & & & & \\
\hline 9. Maternal HRSD & & & & & & & \\
\hline 10. Paternal HRSD & & & & & & & \\
\hline 11. Maternal BDI & & & & & & & \\
\hline 12. Paternal BDI & & & & & & & \\
\hline 13. Maternal stress & & & & & & & \\
\hline 14. Paternal stress & & & & & & & \\
\hline 15. Maternal behavior problems & & & & & & & \\
\hline 16. Paternal behavior problems & & & & & & & \\
\hline$M$ & 11.1 & 18.1 & 9.9 & 9.6 & 7.4 & 6.7 & 1.8 \\
\hline$S D$ & 7.5 & 12.8 & 1.9 & 2.3 & 4.3 & 4.2 & 1.5 \\
\hline
\end{tabular}

Note: BDI = Beck Depression Inventory; HRSD = Hamilton Rating Scale of Depression; LAPS = Lifetime Alcohol Problems Score.

$* p<.10 . * * p<.05 . * * * p<.01 . * * * * p<.001$.

pitalization history section of the questionnaire, and the frequency of illnesses was taken from the prior illnesses and "other problems and symptoms" sections of the questionnaire. Examples of illnesses include frequent and severe headaches, recurrent skin rash, and mononucleosis. The numbers of hospitalizations and illnesses were summed so that higher scores for each reflect more health problems.

\section{Parental Distress}

This construct is composed of three components including an index of current daily hassles (i.e., a current stress index), a measure of self-reported current depression, and an index of current clinical depressive symptoms.

Parental hassles stress. In the present study, paternal and maternal current stress was measured by the Hassles subscale of the self-report Daily Hassles and Uplifts Scale (Kanner, Coyne, Schaefer, \& Lazarus, 1981). This instrument assesses stress experienced in the past month and comprises two subscales: the 117-item Hassles subscale and the 135-item Uplifts subscale. The Hassles subscale measures daily minor stresses, and the Uplifts subscale measures pleasures that characterize everyday life. Each subscale is related to the individual's adaptive functioning (Kanner et al.). For the purposes of the present study, only the frequency score from the Hassles subscale was used. If endorsed, items for this subscale were rated in severity from 1 (somewhat severe) to 3 (very severe). Frequencies of items were summed to reflect higher levels of daily hassles stress. Test-retest correlations are high (e.g., Hassles .79, Kanner et al.).

Parental current depression. Two measures were used to assess current maternal and paternal depression: the short form of the Beck Depression Inventory (BDI; Beck, Rial, \& Rickels, 1974) and the Hamilton Rating Scale (HRSD; Hamilton, 1967). The 13 items of the self-report short-form BDI are rated by each parent on a scale ranging from 0 to 3 , with 0 reflecting higher functioning and 3 reflecting lower functioning. This measure focuses on various areas of functioning known to be affected by depression, such as mood, appetite, and sleep; considerable evidence supports its reliability and validity (Beck, Steer, \& Garbin, 1988). Items are summed, with higher scores reflecting more depression.
The HRSD was used to obtain clinical ratings of maternal and paternal depression. This scale was given during an administration of the NIMH DIS (Robins et al., 1980), and ratings were completed immediately thereafter. Although the HRSD was developed as an observation-based rating scale to be completed by a treatment provider in an institutional setting, research has demonstrated that trained raters administering the instrument in the context of the NIMH DIS displayed excellent agreement with psychiatrist ratings (Whisman et al., 1989). Interrater reliabilities on the current project, based on ratings done after a review of NIMH DIS protocols and audiotapes, demonstrated an acceptable .80 reliability. Higher scores on the HRSD reflect greater current depression.

\section{Child Behavior Problems}

Each parent completed the Child Behavior Checklist (CBCL; Achenbach \& Edelbrock, 1983), which was used to assess behavior problems in the target child during the previous 6 months. Test-retest reliability of the 118-item CBCL has been shown to range from .95 over a 2 -week interval to .84 over a 3month interval, and parent agreement on the CBCL scores falls between .62 and .69 (Achenbach, 1991). External validity of the CBCL also has been reported to be adequate (Bird, Gould, Rubio-Stipec, Staghezza, \& Canino, 1991), with parent CBCL ratings shown to be related to independent raters' perceptions of the child. The CBCL yields scores on two broadband factors reflecting externalizing and internalizing behavior and also provides an overall index of child behavior problems known as the Total Behavior Problems score. For purposes of this study, the Total Behavior Problems raw score was analyzed, with higher scores reflecting more behavior problems.

\section{Measurement Model}

Structural equation modeling was used to test the hypothesized relationships among parental lifetime alcohol-related psychopathology, parental health history, current levels of parent distress, and child behavior problems (see Figure 1). LISREL 8 for Windows (Jöreskog \& Sörbom, 1993) was used to obtain maximum likelihood estimates of the model coefficients, and a covariance matrix was analyzed. Table 1 lists the means, stan- 
Table 1

Extended

\begin{tabular}{|c|c|c|c|c|c|c|c|c|}
\hline 8 & 9 & 10 & 11 & 12 & 13 & 14 & 15 & 16 \\
\hline-.02 & $.24 * * * *$ & $.27 * * * *$ & $.33 * * * *$ & $.21 * * * *$ & $.32 * * * *$ & .07 & $.34 * * * * *$ & $.17 * * *$ \\
\hline .08 & $.17 * * *$ & $.25 * * * *$ & $.13^{* *}$ & $.33 * * * *$ & $.21 * * * *$ & $.20 * * * *$ & $.16^{* * * *}$ & $.27 * * * *$ \\
\hline .07 & $.23 * * * *$ & $.21 * * * *$ & $.16^{* * *}$ & $20 * * * *$ & $.23 * * * *$ & .05 & $.25 * * * *$ & $.18^{* * *}$ \\
\hline .02 & $.15^{* *}$ & $.34 * * * *$ & $.16^{* *}$ & $.33 * * * *$ & $.14 * *$ & $.21 * * * *$ & $.18 * * *$ & $.28 * * * *$ \\
\hline $.22 * * * *$ & $.21 * * * *$ & $.11^{*}$ & $.18 * * *$ & $.15^{* *}$ & $.26^{* * * * *}$ & .09 & $.23 * * * *$ & .05 \\
\hline $.44 * * * *$ & .07 & $.18 * * *$ & $.14 * *$ & $.38 * * * *$ & $.12 *$ & $.33 * * * *$ & $.19 * * *$ & $.20 * * * *$ \\
\hline \multirow[t]{9}{*}{$.16^{* * * *}$} & -.01 & -.03 & -.00 & -.01 & -.09 & -.06 & -.03 & .07 \\
\hline & .05 & .08 & .01 & $.16^{* * * *}$ & .03 & $.15^{* *}$ & .08 & .04 \\
\hline & & $.34 * * * *$ & $.24 * * * *$ & $.17 * * *$ & $.30 * * * *$ & .04 & $.22 * * * *$ & -.04 \\
\hline & & & $.21 * * * *$ & $.43 * * * *$ & $.19 * * *$ & $.25 * * * *$ & .08 & $.14 * *$ \\
\hline & & & & $.40 * * * *$ & $.43 * * * *$ & $.20 * * * *$ & $.30 * * * *$ & $.12 *$ \\
\hline & & & & & $.29 * * * *$ & $.57 * * * *$ & $.30 * * * *$ & $.39 * * * *$ \\
\hline & & & & & & $.35 * * * *$ & $.32 * * * *$ & $.16 * *$ \\
\hline & & & & & & & $.16^{* * *}$ & $.35 * * * *$ \\
\hline & & & & & & & & $.28 * * * * *$ \\
\hline 1.5 & 5.4 & 3.8 & 3.2 & 2.6 & 34.8 & 29.5 & 30.9 & 29.6 \\
\hline 1.4 & 6.2 & 4.5 & 3.4 & 2.9 & 24.2 & 23.1 & 18.0 & 17.2 \\
\hline
\end{tabular}

dard deviations, and correlations for the indicator variables included in the analyses. Prior to testing the hypothesized structural relations among the latent constructs, the fit of the measurement model was evaluated. Measurement and structural models were considered to fit if the resulting $\chi^{2}$ was less than twice as large as the degrees of freedom, if the goodness-of-fit index (GFI) and comparative fit index (CFI) were each greater than .90, and if the root mean square error of approximation (RMSEA) and the standardized root mean square residual (SRMR) were less than .08 (values below .05 indicate good fit, and those between .05 and .08 indicate fair fit; Browne \& $\mathrm{Cu}-$ deck, 1993).

The measurement model for the present study consisted of four latent constructs and 16 indicator variables. The latent constructs were parental alcohol-related psychopathology, parental health history, parental distress, and child behavior problems. Parental alcohol-related psychopathology was indicated by maternal and paternal lifetime alcohol problems and antisocial behavior. Parental health history was indicated by maternal and paternal lifetime illnesses and hospitalizations. Parental distress was indicated by maternal and paternal current stress and depression. Finally, child behavior problems were indicated by maternal and paternal ratings of total child behavior problems.

Results revealed that the measurement model fit the data reasonably well $\left(\chi^{2}[88]=175.95, p<.001 ; \mathrm{GFI}=.92 ; \mathrm{CFI}=\right.$ .91 ; RMSEA $=.06$; SRMR $=.08)$. To further evaluate the adequacy of the measurement model, it was compared to a null measurement model in which none of the associations among the latent variables were modeled. Compared to the null model, the measurement model fit the data significantly better $\left(\Delta \chi^{2}[6]\right.$ $=174.51, p<.001)$. Examination of the resulting measurement model showed that all indicator loadings for the latent constructs were statistically significant. However, the maternal hospitalizations loading for the parent health history construct was only marginally significant $(p<.10)$. Nonetheless, this indicator variable was retained because of its theoretical relevance to parental health problems. Further examination of the resulting measurement model revealed that the latent constructs were more strongly influenced by the paternal indicator variables than they were by the maternal indicators.

\section{Results}

The hypothesis that the associations between history of parental alcohol-related psychopathology, parental health, and child behavior problems would be mediated by current levels of parental distress was tested by comparing two competing models. Structural equation modeling was used to contrast the completely mediated model (hypothesized model) and the mixed effects model. In the mixed effects model, the relations between history of parental alcohol-related psychopathology and child behavior problems and between parental health history and child behavior problems were both direct and were mediated by current parental distress.

The completely mediated model was tested first, and it represented a good fit to the data $\left(\chi^{2}[89]=169.78, p<.001\right.$; GFI $=.93 ; \mathrm{CFI}=.91 ; \mathrm{RMSEA}=.06 ;$ SRMR $=.08)$. Examination of the structural relations revealed that both history of parental alcohol-related psychopathology and history of parental health were positively associated with current parental distress. In turn, parental distress was positively associated with child behavior problems.

The mixed effects model was tested next, and it also resulted in a good fit $\left(\chi^{2}[87]=159.31, p<.001 ; \mathrm{GFI}=.93 ; \mathrm{CFI}=\right.$ .92 ; RMSEA $=.06$; SRMR $=.07)$. Results showed that the association between parental alcohol-related psychopathology and child behavior problems was both direct and indirect. That is, the influence of parent alcohol-related psychopathology was not completely accounted for by current parental distress. Finally, parental health history contributed significantly to parental distress, and, in turn, distress was significantly associated with child behavior problems. To determine the best-fitting model (either completely mediated or mixed effects), the two nested models were compared using a $\chi^{2}$ difference test. The results of the difference test showed that the mixed effects model fit the data significantly better than did the completely mediated model $\left(\Delta \chi^{2}[2]=10.47, p<.001\right)$. The direct path from parental health history to child behavior problems was not significant in the mixed effects model; therefore, it was trimmed to obtain a final model. The final model fit the data well $\left(\chi^{2}[88]=160.47, p<\right.$ .001 ; $\mathrm{GFI}=.93$; CFI $=.92$; RMSEA $=.06$; SRMR $=.07$ ). Figure 2 contains the final trimmed model showing the signifi- 


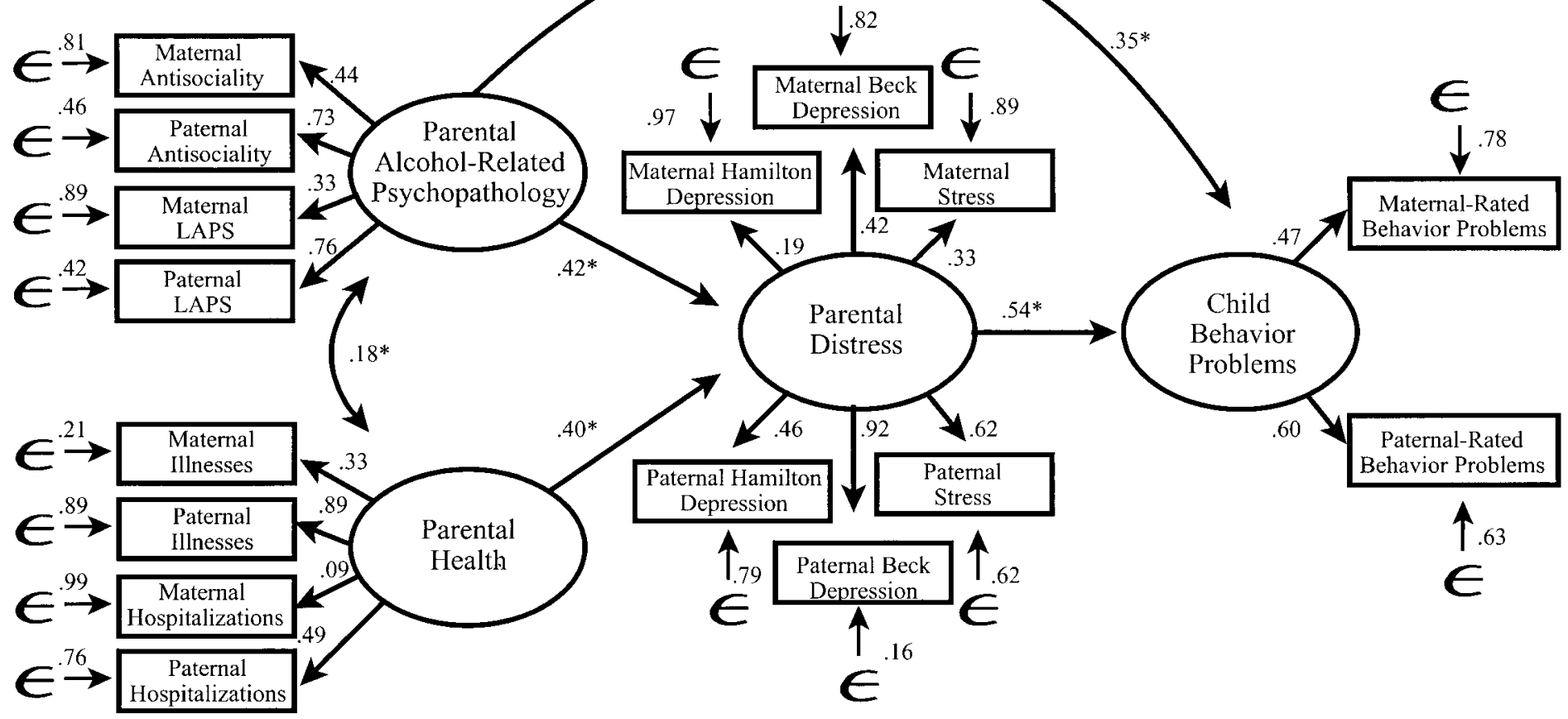

Figure 2. Completely Standardized Solution for the Final Model.

Note: LAPS $=$ Lifetime Alcohol Problems Score. ${ }^{*} p<.05$.

$R^{2}$ of Parental Distress $=.40 ; R^{2}$ of Child Behavior Problems $=.60$.

cant completely standardized coefficients. Because of space constraints, correlations among uniquenesses are not shown in the figure; however, the following uniquenesses were allowed to correlate: maternal LAPS and maternal antisociality (.36), maternal antisociality and maternal BDI (.21), maternal antisociality and maternal stress (.15), paternal LAPS and paternal HRSD (.11), maternal HRSD and maternal stress (.20), maternal HRSD and paternal HRSD (.23), maternal BDI and maternal stress (.26), maternal stress and paternal stress (.18), maternal illnesses and maternal hospitalizations (.23), maternal illnesses and maternal HRSD (.17), maternal illnesses and maternal stress (.20).

\section{Discussion}

The present study examined the associations among history of parental alcohol-related psychopathology, health problems, current levels of parental distress, and child behavior problems. The results supported the hypothesis that parental distress would mediate the relations between history of parental alcohol-related psychopathology, parental health, and child behavior problems. However, a direct association also existed between parental lifetime alcohol-related psychopathology and child behavior problems, corroborating previous research indicating that parental alcoholism and antisocial behavior heighten risk for offspring behavioral difficulties (Chassin, Rogosch, \& Barrera, 1991; Kuperman et al., 1999; West \& Prinz, 1987). Previous researchers have suggested that children may learn directly from their parents how to interact in everyday situations and thus that children who show increased levels of behavior problems are socialized to behave in a coercive and antisocial manner (Patterson, 1992).
This socialization process may be particularly salient for children of alcoholic and antisocial parents, because not only are such parents likely to model inappropriate behaviors for their young sons, but they also may be likely to engage in coercive behaviors with them (Zucker, Ellis, Bingham, et al., 1996).

In addition to the role of familial socialization in the development of sons' behavioral problems, it also is possible that heritable individual differences, in part, underlie the direct relation between parental alcohol-related psychopathology and child behavior. Although this could not be tested in the present research, findings from physiological studies, as well as those from twin and adoption studies, have demonstrated that genetic and biological mechanisms play an important role in this relation (Iacono, 1998). However, the significant direct association indicates that parental distress does not completely account for the relationship between parental lifetime alcohol-related psychopathology and child behavior problems. Rather, other variables not included in the present study may also potentially mediate this association. For instance, important mediators that should be tested in future studies include child individual difference variables, such as temperament and cognitive ability, as well as family environment variables, such as family conflict and parentchild interaction quality.

Further findings showed that a history of health problems was not directly associated with child outcome. Instead, health history was indirectly associated with child behavior problems either through parental alcohol-related psychopathology or parental distress. The positive association between parental alcohol-related psychopathology and health history parallels previous 
research findings showing that individuals with alcohol-related psychopathology and their families are at heightened risk for poor health outcomes (e.g., Engs \& Aldo-Benson, 1995; Roberts \& Brent, 1982). Previous studies have indicated that an alcoholic lifestyle — characterized by poor eating habits, erratic sleeping patterns, and increased incidence of accidents (Dufour \& Caces, 1993; Engs \& Aldo-Benson; Marsano, 1993)_may play a role in worsening health. Alternatively, poor health may be caused by the direct suppressing effects of alcohol on the immune system (Grossman \& Wilson, 1992; Roselle, 1992).

Health history also may function to increase parental distress, which, in turn, is directly related to increased levels of child behavior problems. This result is consistent with our hypothesis, suggesting that parental distress (not health history) is the pathway through which child behavior problems are affected. Parents who report elevated levels of stress and depression may be at risk for using harsh and coercive discipline techniques to control chaotic family environments and may fail to appropriately monitor their child's behaviors (Patterson \& Capaldi, 1991). For instance, previous studies have reported that depressed mothers are more negative toward their children, more critical, more nagging, and more physically abusive than are nondepressed mothers (see Cummings \& Davies, 1994, for a review). Each of these factors has been found to contribute to the development of child behavioral difficulties.

However, it should be noted that parental distress also may contribute to the worsening of parental physical health problems (see Baum \& Posluszny, 1999). Although the cross-sectional design of the current study did not allow assessment of the bidirectional relationship that likely exists between parental health and distress, future studies should address this issue through use of longitudinal data. The current results contradict Stein and Newcomb's (1994) findings that parental physical symptomatology is directly related to child behavior problems. One possible reason for this discrepancy is methodological: Stein and Newcomb's study included only mothers and their 2- to 10-year-old children. The present study included mothers and fathers of children aged $3-5$, and the majority of the sample was drawn from a high-risk population.

Findings of the current study draw attention to parental physical health as a correlate of parental alcohol-related psychopathology and as yet another factor that may increase risk for the development of behavioral problems among young sons of alcoholics. Specifically, results showed that increased levels of parental alcohol-related psychopathology and co-occurring physical health problems are indirectly related to child behavioral problems through current levels of parental distress. Parental health history should be included in further studies to delineate the processes by which it is related to child outcome. Overall, this study demonstrated that individuals who experience elevated levels of alcohol-related psychopathology and a history of health problems also report more current levels of stress and depression, which, in turn, are associated with the development of behavior problems in preschool-aged boys.

\section{Future Directions}

Although a strength of the present work is the inclusion of paternal ratings of child behavior problems in addition to maternal ratings (Phares \& Compas, 1992), future studies should include additional methods of assessment, such as behavioral observation methods or third-party reports. Behavioral observation methods may be especially important, because previous re- searchers have questioned the accuracy of parent reports of child behaviors (Sawyer, Steiner, \& Baghurst, 1998), particularly those provided by parents experiencing elevated levels of depression or other psychopathology (e.g., Webster-Stratton, 1988). To date, although no conclusive evidence has been provided to show that parents who are depressed inaccurately perceive their child's behaviors, it is likely that parental ratings of child behaviors are influenced by the context in which the parent and child interact and also by the amount of time the parent spends with his or her child (Fitzgerald, Zucker, Maguin, \& Reider, 1994). As children increase in age, they spend less time with parents and more time interacting in multiple settings outside the home (Maccoby, 1984), thereby increasing the importance of obtaining reports from other raters such as teachers and peers.

The use of a community-based sample of alcoholic families is an additional strength of the present study. However, generalization of the results is restricted to the non-Hispanic White population. Future studies examining the development of child behavior problems in high-risk alcoholic samples should include ethnic and racial groups other than Caucasian. In addition, objective sources of parental health history information, such as official medical records, would ensure greater accuracy than is obtained through retrospective self-reports.

Data for the present study were cross-sectional, and thus causality cannot be inferred from our results. Moreover, some of the relations in the final model are likely to be bidirectional. For instance, although the main focus of the current study was the influence of parental functioning on child behavioral problems, it is likely that child behaviors also influence parent behaviors and adjustment (e.g., Lytton, 1990). Thus, follow-up studies should be conducted that use a prospective research design, obtain multiple measurements of the study constructs across time, and map the developmental unfolding of child behavioral problems.

\section{Implications for Practitioners}

Findings from the present study demonstrate that parental alcohol problems and antisocial behavior are associated with elevated rates of parental health problems and distress and with child behavioral problems. Specifically, parental distress acts as a variable that mediates or accounts for the relations between parental alcohol-related psychopathology and health and behavioral problems in 3- to 5-year-old sons. However, parental distress does not completely account for the relation between parent alcohol-related psychopathology and child outcome. Rather, parental alcoholism and co-occurring antisocial behavior are directly associated with the son's behavioral difficulties. Practitioners should be aware that parent alcoholism with comorbid antisocial behavior may exacerbate risk for negative developmental outcomes for a portion of young male COAs. Parents who are antisocial and alcoholic report increased levels of distress, which, in turn, may undermine their ability to provide appropriate parenting to young sons and also to monitor their behaviors. Not only do distressed parents expose their children to coercive and antisocial behaviors, but they also may reinforce similar behaviors in their children. Research regarding genderspecific parenting behaviors suggests this may be especially true of fathers and their young male children.

Providing information and training to parents regarding appropriate family management techniques may reduce child behavior problems. Existing research shows that training parents to use consistent monitoring and discipline techniques as well as training them to reinforce child prosocial behaviors may be especially ef- 
fective in reducing their son's conduct problems (Nye, Zucker, \& Fitzgerald, 1999). Helping parents understand the importance of modeling appropriate behaviors might also reduce their child's risk for later behavioral difficulties. Parents who are highly distressed may have difficulty dealing with their anger in a socially acceptable, nonaggressive manner; thus, teaching them to use angercontrol and problem-solving strategies may increase their own self-control and, importantly, would also provide their children with models of appropriate behavior (see Conduct Problems Prevention Research Group, 1992). Finally, because behavior problems that appear early in development are highly stable across time and are likely to persist, it is important to identify children exhibiting such problems (e.g., hyperactivity, impulsivity, aggression, excessive noncompliance, and irritability) early in the preschool years so interventions focused on strengthening family management techniques can be provided (Campbell, 1995).

\section{References}

Achenbach, T. M. (1991). Manual for the Child Behavior Checklist/4-18 and 1991 profile. Burlington: Department of Psychiatry, University of Vermont.

Achenbach, T. M., \& Edelbrock, C. (1983). Manual for the Child Behavior Checklist and revised child behavior profile. Burlington: Department of Psychiatry, University of Vermont.

Ahles, T. A., Khan, S. A., Yunus, M. B., Spiegel, D. A., \& Masi, A. T. (1991). Psychiatric status of patients with primary fibromyalgia, patients with rheumatoid arthritis, and subjects without pain: A blind comparison of DSM-III diagnoses. American Journal of Psychiatry, 148, 1721-1726.

Armistead, L., Klein, K., \& Forehand, R. (1995). Parental physical illness and child functioning. Clinical Psychology Review, 15, 409-422.

Babor, T. F., Holmann, M., Delboca, F., Hesselbrock, V., Meyer, R., Dolinsky, Z., \& Rounsaville, B. (1992). Types of alcoholics: I. Evidence of an empirically derived typology based on indicators of vulnerability and severity. Archives of General Psychiatry, 49, 599-608.

Banks, S. M., \& Kerns, R. D. (1996). Explaining high rates of depression in chronic pain: A diathesis-stress framework. Psychological Bulletin, 119, 95110.

Baum, A., \& Posluszny, D. M. (1999). Health psychology: Mapping biobehavioral contributions to health and illness. Annual Review of Psychology, 50, 137-163.

Beck, A., Rial, W., \& Rickels, K. (1974). Short form of the Beck Depression Inventory. Psychological Reports, 34, 1184-1186.

Beck, A., Steer, R., \& Garbin, M. (1988). Psychometric properties of the Beck Depression Inventory: Twenty-five years of evaluation. Clinical Psychology Review, 8, 77-100.

Bird, H., Gould, M., Rubio-Stipec, M., Staghezza, B., \& Canino, G. (1991). Screening for childhood psychopathology in the community using the Child Behavior Checklist. Journal of the American Academy of Child and Adolescent Psychiatry, 30, 116-123.

Browne, M. W., \& Cudeck, R. (1993). Alternative ways of assessing model fit. In K. Bollen \& K. Long (Eds.), Testing structural equation models (pp. 136162). Newbury Park, CA: Sage.

Campbell, S. B. (1995). Behavior problems in preschool children: A review of recent research. Journal of Child Psychology and Psychiatry, 36, 113-149.

Carpenter, J. A., \& Lester, D. (1980). The etiology of alcoholism: A longitudinal study. New Brunswick, NJ: Rutgers Center of Alcohol Studies.

Chassin, L., Rogosch, F., \& Barrera, M. (1991). Substance use and symptomatology among adolescent children of alcoholics. Journal of Abnormal Psychology, 100, 449-463.

Chou, P. S., Grant, B. F., \& Dawson, D. A. (1996). Medical consequences of alcohol consumption-United States, 1992. Alcoholism: Clinical and Experimental Research, 20, 1423-1429.

Cloninger, R. C. (1987). Neurogenetic adaptive mechanisms in alcoholism. Science, 236, 410-416.

Conduct Problems Prevention Research Group. (1992). A developmental and clinical model for the prevention of conduct disorder: The FAST Track Program. Development and Psychopathology, 4, 509-527.

Cummings, E. M., \& Davies, P. T. (1994). Maternal depression and child development. Journal of Child Psychology and Psychiatry, 35, 73-112.

DeLongis, A., Coyne, J. C., Dakof, G., Folkman, S., \& Lazarus, R. S. (1982). Relationships of daily hassles, uplifts, and major life events to health status. Health Psychology, 1, 119-136.
Dufour, M. C., \& Caces, M. F. (1993). Epidemiology of the medical consequences of alcohol. Alcohol Health and Research World, 17, 265-271.

Engs, R. C., \& Aldo-Benson, M. (1995). The association of alcohol consumption with self-reported illness in university students. Psychological Reports, 76, 727-736.

Feighner, J. P., Robins, E., Guze, S., Woodruff, R. A., Winokur, G., \& Munoz, R. (1972). Diagnostic criteria for use in psychiatric research. Archives of General Psychiatry, 26, 57-63.

Fitzgerald, H. E., Zucker, R. A., Maguin, E. T., \& Reider, E. E. (1994). Time spent with child and parental agreement about preschool children's behavior. Perceptual and Motor Skills, 79, 336-338.

Glenn, S. W., Parsons, O. A., \& Stevens, L. (1989). Effects of alcohol abuse and familial alcoholism on physical health in men and women. Health Psychology, 8, 325-341.

Grossman, C. J., \& Wilson, E. J. (1992). The immune system: Mechanisms that counteract disease. Alcohol Health and Research World, 16, 5-22.

Hamilton, M. (1967). Standardized assessment and recording of depressive symptoms. Psychiatry, Neurology and Neurosurgery, 72, 201-205.

Hammen, C. (1992). Life events and depression: The plot thickens. American Journal of Community Psychology, 20, 179-193.

Harnish, J. D., Dodge, K. A., \& Valente, E. (1995). Mother-child interaction quality as a partial mediator of the roles of maternal depressive symptomatology and socioeconomic status in the development of behavior problems. Child Development, 66, 739-753.

Iacono, W. G. (1998). Identifying psychophysiological risk for psychopathology: Examples from substance abuse and schizophrenia research. Psychophysiology, 35, 621-637.

Johnson, S. L., \& Jacob, T. (1995). Psychosocial functioning in children of alcoholic fathers. Psychology of Addictive Behaviors, 9, 101-113.

Jöreskog, K. G., \& Sörbom, D. (1993). LISREL VIII: User's reference guide. Chicago: Scientific Software International.

Kanner, A. D., Coyne, J. C., Schaefer, C., \& Lazarus, R. S. (1981). Comparison of two modes of stress measurement: Daily hassles and uplifts versus major life events. Journal of Behavioral Medicine, 4, 1-39.

Kuperman, S., Schlosser, S. S., Lidral, J., \& Reich, W. (1999). Relationship of child psychopathology to parent alcoholism and antisocial personality disorder. Journal of the American Academy of Child and Adolescent Psychiatry, 38, 686-692.

Lazarus, R. S., \& Folkman, S. (1984). Stress, appraisal, and coping. New York: Springer.

Lytton, H. (1990). Child and parent effects in boys' conduct disorder: A reinterpretation. Developmental Psychology, 26, 683-697.

Maccoby, E. E. (1984). Middle childhood in the context of the family. In A. W. Colins (Ed.), Development during middle childhood (pp. 184-239). Washington, DC: National Academy Press.

Marsano, L. (1993). Alcohol and malnutrition. Alcohol Health and Research World, 17, 284-291.

Nye, C. L., Zucker, R. A., \& Fitzgerald, H. E. (1999). Early family-based intervention in the path to alcohol problems: Rationale and relationship between treatment process characteristics and child and parenting outcomes. Journal of Studies on Alcohol, 13(Suppl.), 10-21.

Patterson, G. R. (1992). Developmental changes in antisocial behavior. In R. D. Peters, R. J. McMahon, \& V. L. Quinsey (Eds.), Aggression and violence throughout the lifespan (pp. 52-82). New York: Sage.

Patterson, G. R., \& Capaldi, D. M. (1991). Antisocial parents: Unskilled and vulnerable. In P. A. Cowan \& E. M. Hetherington (Eds.), Family transitions (pp. 195-216). Hillsdale, NJ: Erlbaum.

Phares, V., \& Compas, B. E. (1992). The role of fathers in child and adolescent psychopathology: Make room for daddy. Psychological Bulletin, 111, 387412.

Puttler, L. I., Zucker, R. A., Fitzgerald, H. E., \& Bingham, C. R. (1998). Behavioral outcomes among children of alcoholics during the early and middle childhood years: Familial subtype variations. Alcoholism: Clinical \& Experimental Research, 22, 1962-1972.

Reich, W., Earls, F., \& Powell, J. (1988). A comparison of the home and social environments of children of alcoholic and non-alcoholic parents. British Journal of Addiction, 83, 831-839.

Roberts, K. S., \& Brent, E. E. (1982). Physician utilization and illness patterns in families of alcoholics. Journal of Studies on Alcohol, 43, 119-128.

Robins, L. M., Helzer, J. H., Croughn, J., \& Ratcliffe, K. S. (1980). National Institute of Mental Health Diagnostic Interview Schedule: Its history, characteristics, and validity. Archives of General Psychiatry, 38, 381-389.

Roselle, G. A. (1992). Alcohol and the immune system. Alcohol Health and Research World, 16, 16-22.

Rubio-Stipec, M., Bird, H. G., Canino, G. J., Bravo, M., \& Alegria, M. (1991). 
Children of alcoholic parents in the community. Journal of Studies on Alcohol, 52, 78-88.

Sawyer, M. G., Steiner, D. L., \& Baghurst, P. (1998). The influence of distress on mothers and fathers reports of childhood emotional and behavioral problems. Journal of Abnormal Child Psychology, 26, 407-414.

Selzer, M. L. (1975). A self-administered Short Michigan Alcohol Screening Test (SMAST). Journal of Studies on Alcohol, 36, 117-126.

Siegal, M. (1987). Are sons and daughters treated more differently by fathers than by mothers? Developmental Review, 7, 183-209.

Stein, J. A., \& Newcomb, M. D. (1994). Children's internalizing and externalizing behaviors and maternal health problems. Journal of Pediatric Psychology, 19, 571-594.

Webster-Stratton, C. (1988). Mothers' and fathers' perceptions of child deviance: Roles of parent and child behaviors and parent adjustment. Journal of Consulting and Clinical Psychology, 56, 909-915.

West, M. O., \& Prinz, R. J. (1987). Parental alcoholism and childhood psychopathology. Psychological Bulletin, 102, 204-218.

Whisman, N., Strosahl, K., Fruzetti, A., Schmaling, K., Jacobson, N., \& Miller, D. (1989). A structured interview version of the Hamilton Rating Scale for Depression: Reliability and validity. Psychological Assessment, 1, 234-241.

Zucker, R. A. (1991). Scaling the developmental momentum of alcoholic process via the Lifetime Alcohol Problems Score. Alcohol and Alcoholism, 1(Suppl.), 505-510.

Zucker, R. A., \& Barron, F. H. (1973). Parental behaviors associated with problem drinking and antisocial behavior among adolescent males. In M. E. Chafetz (Ed.), Proceedings of the First Annual Alcoholism Conference of the National Institute on Alcohol Abuse and Alcoholism. Research on alcoholism: I. Clinical problems and special populations (pp. 276-296). Rockville, MD National Institute on Alcohol Abuse and Alcoholism.

Zucker, R. A., Davies, W. H., Kincaid, S. B., Fitzgerald, H. E., \& Reider, E. E. (1997). Conceptualizing and scaling the developmental structure of behavior disorder: The Lifetime Alcohol Problems Score as an example. Development and Psychopathology, 9, 453-471.

Zucker, R. A., Ellis, D. A., Bingham, C. R., \& Fitzgerald, H. E. (1996). The development of alcoholic subtypes: Risk variation among alcoholic families during the early childhood years. Alcohol Health \& Research World, 20, 46-54.

Zucker, R. A., Ellis, D. A., \& Fitzgerald, H. E. (1994). Developmental evidence for at least two alcoholisms: I. Biopsychosocial variation among pathways into symptomatic difficulty. Annals of the New York Academy of Sciences, 708, 134-146.
Zucker, R. A., Ellis, D. A., Fitzgerald, H. E., Bingham, C. R., \& Sanford, K. (1996). Other evidence for at least two alcoholisms: II. Life course variation in antisociality and heterogeneity of alcoholic outcome. Development and Psychopathology, 8, 831-848.

Zucker, R. A., Fitzgerald, H. E., \& Noll, R. B. (1990). Drinking and drug history (Rev. ed., version 4). Unpublished instrument, Michigan State University, East Lansing.

Zucker, R. A., Fitzgerald, H. E., Refior, S. K., Puttler, L. I., Pallas, D. M., \& Ellis, D. A. (2000). The clinical and social ecology of childhood for children of alcoholics: Description of a study and implications for a differentiated social policy. In H. E. Fitzgerald, B. M. Lester, \& B. S. Zuckerman (Eds.), Children of addiction: Research, health, and policy issues. New York: Garland Press.

Zucker, R. A., \& Noll, R. B. (1980). The Antisocial Behavior Checklist. Unpublished instrument, Michigan State University, East Lansing.

Zucker, R. A., Noll, R. B., Ham, H. P., Fitzgerald, H. E., \& Sullivan, L. S. (1994). Assessing antisociality with the Antisocial Behavior Checklist: Reliability and validity studies. Unpublished manuscript, University of Michigan, Ann Arbor, and Michigan State University, East Lansing.

Alexandra Loukas is Assistant Professor in the Department of Kinesiology \& Health Education at the University of Texas at Austin, Austin, TX.

Lisa A. Piejak is School Psychologist in the Early Intervention and Preprimary Programs in the Troy School District, Troy, MI.

C. Raymond Bingham is Assistant Research Scientist in the Department of Psychiatry at the University of Michigan and Research Investigator at the Department of Veterans Affairs, Ann Arbor, MI.

Hiram E. Fitzgerald is Professor in the Department of Psychology at Michigan State University, East Lansing, MI.

Robert A. Zucker is Professor of Psychology in the Departments of Psychiatry and Psychology and the Alcohol Research Center at the University of Michigan, Ann Arbor, MI. 